\title{
Forced degradation studies
}

\begin{abstract}
Forced degradation studies include the degradation of new drug substance and drug product at conditions more severe than accelerated conditions. These studies illustrate the chemical stability of the molecule which further facilitates the development of stable formulation with suitable storage conditions. ICH guidelines demonstrate certain degradation conditions like light, oxidation, dry heat, acidic, basic, hydrolysis etc. ICH Q1A, QIB and Q2B exemplify the forced degradation studies. This review overviews the strategic approaches and trends in forced degradation studies.
\end{abstract}

Keywords: degradation, drug substance, stability, safety, testing, ich guidelines, fda
Volume 3 Issue 6 - 2016

\author{
Farah Iram, Huma Iram, Azhar lqbal,Asif \\ Husain \\ Department of Pharmaceutical Chemistry, Jamia Hamdard \\ (Hamdard University), India
}

Correspondence: Asif Husain, Department of Pharmaceutical Chemistry, Faculty of Pharmacy, Jamia Hamdard (Hamdard University), New Delhi, India,

Email ahusain@jaimiahamdard.ac.in

Received: November 0I, 2016 | Published: December 14, 2016

\section{Introduction}

Forced degradation studies provide the approach to analyse the stability of drug samples in pharmaceutical industries. Drug product safety and efficacy is affected by the chemical stability of the molecule. Stability of molecule information provides the data for selecting proper formulation, package, proper storage conditions and shelf life. These data also play a significant role which is required in the regulatory documentation. Before filling registration dossier it is obligatory to execute stability studies of new drug molecules. ${ }^{1,2}$

International Conference on Harmonisation (ICH) guidelines, make it essential to organize the forced degradation studies and it is evidently mandated to perform forced degradation of new drug products. These studies offer the information to support detection of potential degradants. It also illustrates the degradation pathways of pharmaceutically active molecules. The drug molecule intrinsic stability can be estimated by forced degradation studies. Probable polymorphic or enantiomeric substances and variation between drug related degradation and excipients interferences can also be evaluated by forced degradation studies. ${ }^{3,4}$ ICH guidelines mandatory oblige the forced degradation studies under a range of conditions, like $\mathrm{pH}$, light, oxidation, dry heat, acidic, basic, hydrolysis etc. Moreover, it provides the separation of drug from degradation products. The FDA and ICH guidance mandate the requirement of forced degradation to recognize how the quality of a drug substance and drug product varies with time and different environmental factors. ${ }^{5,6}$

The developed and validated analytical method permits the analysis of each degradation products. Unfortunately, there is less guidance available to establish true selective forced degradation methods. Appropriate experimental conditions for forced degradation studies (temperatures, duration, and extent of degradation, etc.) are not specified properly. This review provides an overview of forced degradation under variety of environmental factors. ${ }^{7-9}$

\section{Outcomes of forced degradation studies}

Forced degradation studies offer the following information: ${ }^{2,3,10}$

a. Determination of likely degradants,

b. Determination of degradation pathways,

c. Determination of intrinsic stability of the drug molecule,

d. Determination of validated stability indicating analytical methods.

\section{Regulatory guidelines}

Various International guidelines recommended forced degradation studies ICH guidelines sometimes apply only to the marketing applications for new products and do not cover the part during clinical development. The ICH guidelines that are applicable to forced degradation studies are: ${ }^{1,6,10}$

a. ICH Q1A: Stability Testing of New Drug Substances and Products,

b. ICH Q1B: Photo stability Testing of New Drug Substances and Products,

\section{c. ICH Q2B: Validation of Analytical Procedures: Methodology.}

ICH Q1A (Stress testing): Recommended conditions for performing forced degradation studies on drug substances and drug products. The recommendations are to inspect the results of temperature (above that for accelerated testing, i.e., $>50 \mathrm{C}$ ), humidity ( $75 \%$ relative humidity), oxidation and photolysis. Wide $\mathrm{pH}$ range should be considered in the testing of solution or suspension. Ultimately the stability-indicating method developed by these samples. ${ }^{2,11}$

ICH Q1B: Recommended approaches to assessing the photo stability of drug substances and drug products. For drug substance and drug product forced degradation conditions are specified in Section II and Section III respectively. Forced degradation studies exposure levels are not defined. Solid or in solution/suspension, photo stability testing can be performed. These samples are then used to develop a stability indicating method. Some of the degradation products formed during forced degradation studies may not really be experiential to form during stability studies in which case they need not be examined further. ${ }^{1,12}$

ICH Q2B: Gives guidance to validate the analytical methodology. To prove specificity, in section B 1.2.2 (impurities not available) there is a suggestion to utilize samples from forced degradation studies. Whether the analytical method is stability indicating or not 'specificity' is a key factor. ${ }^{6}$

ICH Q3A (R2): with respect to both chemistry and safety prospects the identification of each impurity is required. The chemical prospects include classification and identification of impurities, report creation, catalogue of impurities in the specification and a concise discussion of analytical methods. The safety prospects include specific guidance 
for qualifying those impurities that were not present or were present at significantly minor levels in batch of a new drug substance. ${ }^{11-13}$

\section{Objective for forced degradation: ${ }^{5,14-16}$}

a. To develop degradation pathways of drug substances and drug products.

b. To recognize the chemical properties of drug molecules.

c. To elucidate the structure of degradation products.

d. To resolve stability-related problems

e. To establish the intrinsic stability of a drug substance in the formulation.

f. To reveal the degradation mechanisms of the drug substance and drug product.

g. To distinguish degradation products that is related to drug products from those that are generated from non-drug product in a formulation.

h. To generate stability indicating nature of a developed method.

i. To produce more stable formulations. It also helps in determining the expiry date of a particular formulation.

j. To generate a degradation profile similar to that of what would be observed in a formal stability study under ICH conditions.

\section{When to perform forced degradation studies?}

To perform forced degradation studies for the development of new drug substance and new drug product the time to perform it is very imperative. According to FDA guidance, phase III of the regulatory submission process is the prominent time for these studies. To establish the stability of the drug substance forced degradation studies should be done in different $\mathrm{pH}$ solutions, in the presence of oxygen and light, and at elevated temperatures and humidity levels. The forced degradation studies are conducted on a single batch. The outcomes should be summarized and submitted in an annual report. ${ }^{17}$ The stability studies include two types of studies that is long term studies (12months) and accelerated stability studies (6months). But intermediate studies (6months) can be performed at conditions lesser than that used in accelerated studies. After stability studies the separation, identification and quantitation are carried out. ${ }^{18,19}$

Forced degradation in pre-clinical phase or phase I of clinical trial is encouraged, which provides sufficient time for identifying degradation products, structure elucidation and optimizing the stress conditions. ${ }^{20-22}$ Improvement in the manufacturing process and proper selection of stability-indicating analytical procedures is obtained by early forced degradation studies. According to FDA the forced degradation studies performed: ${ }^{20,23}$

During pre-IND: During formulation Studies: stability indicating quality attributes, degradation routes. For pre-clinical studies: degradants, identification of toxic components.

\section{During clinical development:}

a. Comparing pre-clinical to clinical quality

b. Comparing pre- to post- manufacturing changes

c. In-use stability

Post-marketing: usually studies are not performed but following points considered-
a. Identified new stresses
b. Manufacturing changes
c. Additional indications

\section{Strategic development of Forced Degradation:}

The structural multiplicity of drug molecules makes it difficult to develop the generic set of conditions for a forced degradation study. The selected stress conditions should be reliable with the product's decomposition. ${ }^{8}$ The selected condition should include products property and its degradation under normal manufacturing, storage and use conditions. General protocol Figure 2 illustrates the approach for forced degradation. ${ }^{1,6}$

Forced degradation factors necessary include acid and base hydrolysis, thermal degradation, photolysis, and oxidation and may include freeze-thaw cycles and shear. General conditions used for forced degradation were illustrated in table $1.1,6,24$

Table I Conditions for Forced Degradation Studies

\begin{tabular}{|c|c|c|c|}
\hline $\begin{array}{l}\text { Degradation } \\
\text { Type }\end{array}$ & $\begin{array}{l}\text { Experimental } \\
\text { Conditions }\end{array}$ & $\begin{array}{l}\text { Storage } \\
\text { Conditions }\end{array}$ & $\begin{array}{l}\text { Sampling } \\
\text { Time } \\
\text { (days) }\end{array}$ \\
\hline \multirow[t]{6}{*}{ Hydrolysis } & $\begin{array}{l}\text { Control API (no acid } \\
\text { or base) }\end{array}$ & $40^{\circ} \mathrm{C}, 60^{\circ} \mathrm{C}$ & $\mathrm{I}, 3,5$ \\
\hline & $0.1 \mathrm{M} \mathrm{HCl}$ & $40^{\circ} \mathrm{C}, 60^{\circ} \mathrm{C}$ & $1,3,5$ \\
\hline & $0.1 \mathrm{M} \mathrm{NaOH}$ & $40^{\circ} \mathrm{C}, 60^{\circ} \mathrm{C}$ & $1,3,5$ \\
\hline & Acid control (no API) & $40^{\circ} \mathrm{C}, 60^{\circ} \mathrm{C}$ & $1,3,5$ \\
\hline & Base control (no API) & $40^{\circ} \mathrm{C}, 60^{\circ} \mathrm{C}$ & $\mathrm{I}, 3,5$ \\
\hline & $\mathrm{pH}: 2,4,6,8$ & & $1,3,5$ \\
\hline \multirow[t]{5}{*}{ Oxidation } & $3 \% \mathrm{H} 2 \mathrm{O} 2$ & $25^{\circ} \mathrm{C}, 60^{\circ} \mathrm{C}$ & $1,3,5$ \\
\hline & Peroxide control & $25^{\circ} \mathrm{C}, 60^{\circ} \mathrm{C}$ & $1,3,5$ \\
\hline & $\begin{array}{l}\text { Azobisisobutyronitrile } \\
\text { (AIBN) }\end{array}$ & $25^{\circ} \mathrm{C}, 60^{\circ} \mathrm{C}$ & $1,3,5$ \\
\hline & AIBN control & $25^{\circ} \mathrm{C}, 60^{\circ} \mathrm{C}$ & $1,3,5$ \\
\hline & & $25^{\circ} \mathrm{C}, 60^{\circ} \mathrm{C}$ & $\mathrm{I}, 3,5$ \\
\hline \multirow[t]{3}{*}{ Photolytic } & Light $\mathrm{I} \times \mathrm{ICH}$ & NA & $\mathrm{I}, 3,5$ \\
\hline & Light $3 \times \mathrm{ICH}$ & NA & $1,3,5$ \\
\hline & Light $3 \times \mathrm{ICH}$ & NA & $1,3,5$ \\
\hline \multirow[t]{4}{*}{ Thermal } & Heat chamber & $60^{\circ} \mathrm{C}$ & $1,3,5$ \\
\hline & Heat chamber & $60^{\circ} \mathrm{C} / 75 \% \mathrm{RH}$ & $1,3,5$ \\
\hline & Heat chamber & $60^{\circ} \mathrm{C}$ & $1,3,5$ \\
\hline & Heat chamber & $60^{\circ} \mathrm{C} / 75 \% \mathrm{RH}$ & $1,3,5$ \\
\hline
\end{tabular}

\section{Various degradation conditions}

Hydrolysis: Over a wide range of $\mathrm{pH}$ most common degradation, chemical reactions are Hydrolysis The decomposition of a chemical compound by reaction with water is called Hydrolysis. In acidic and basic hydrolysis the catalysis of ionisable functional groups present in the molecule occurs. Forced degradation of a drug substance occurs when the drug interacts with acid and base. It produces primary degradants in the desirable range. Depending on the stability of the drug substance the class and concentrations of acid or base taken should be decided. For acid hydrolysis hydrochloric acid or sulphuric acids $(0.1-1 \mathrm{M})$ considered to be most suitable whereas sodium hydroxide or potassium hydroxides $(0.1-1 \mathrm{M})$ for base hydrolysis are suggested. ${ }^{8,25} \mathrm{Co}$-solvents can be used if compounds are poorly soluble in water. Forced degradation started at room temperature and further temperature increased if there is no degradation. ${ }^{25}$ 
Oxidation conditions: For oxidative forced degradation, hydrogen peroxide is broadly used. Apart from this as metal ions, oxygen, and radical initiators: azobi-isobutyro-nitrile, AIBN can also be used. Drug structure will allow selecting concentration and condition of oxidizing agents. An electron transfer mechanism occurs in the oxidative degradation of drug substance. ${ }^{26}$

Photolytic conditions: The light exposure does not affect the drug substance for this purpose photo stability is conducted. Photo stability studies are performed to produce primary degradants of drug substance by exposure to UV or fluorescent conditions. In ICH guidelines some recommended conditions for photo stability testing are described. ${ }^{27}$

Samples of drug substance and solid/liquid drug product should be exposed to a minimum of 1.2 million $\mathrm{lx} \mathrm{h}$ and $200 \mathrm{~W} \mathrm{~h} / \mathrm{m} 2$ light $300-800 \mathrm{~nm}$ is the most commonly accepted wavelength of light to cause the photolytic degradation. ${ }^{28} 6$ million $1 \mathrm{xh}$ is the maximum illumination recommended. Photo oxidation can be caused by light stress conditions by the free radical mechanism. Photosensitive groups are carbonyls, nitroaromatic, N-oxide, alkenes, aryl chlorides, weak $\mathrm{C}-\mathrm{H}$ and $\mathrm{O}-\mathrm{H}$ bonds, sulfides and polyenes. ${ }^{29}$

Thermal conditions: Thermal degradation (e.g., dry heat and wet heat) should be carried out at more strenuous conditions than recommended ICH Q1A accelerated testing conditions. Samples of solid-state drug substances and drug products should be exposed to dry and wet heat. Liquid drug products should be exposed to dry heat. For a shorter period studies may be conducted at higher temperatures. Through the Arrhenius equation the effect of temperature on thermal degradation of a substance can be studied. ${ }^{30}$

Where $\mathrm{k}$ is specific reaction rate, $\mathrm{A}$ is frequency factor, Ea is energy of activation, $\mathrm{R}$ is gas constant $(1.987 \mathrm{cal} / \mathrm{deg} \mathrm{mol}), \mathrm{T}$ is absolute temperature. Thermal degradation study is carried out at $40-80^{\circ} \mathrm{C}$.

Humidity: Humidity is one of the effective factors in establishing the potential degradants in the finished product and active pharmaceutical ingredient. Normally $90 \%$ humidity for the duration of one week shall be recommended for the establishment of forced degradation samples. ${ }^{31}$

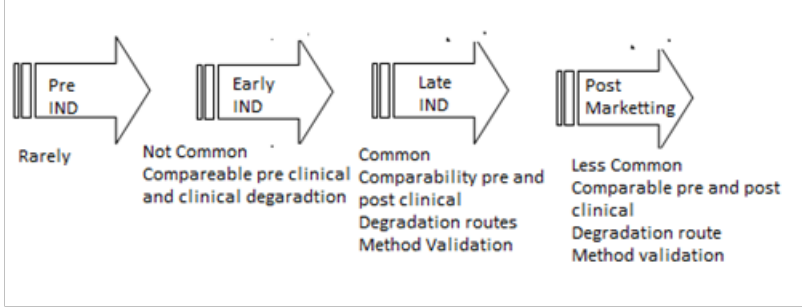

Figure I Forced Degradation Submitted Data.

Total degradation occur

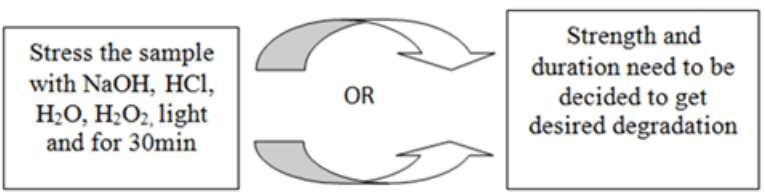

No degradation occur

Figure 2 Approach for Forced Degradation.

\section{Characterization by analytical techniques}

Various methods can be used for the identification and characterization of forced degradation products. Most chosen method of analysis for a stability indicating assay is reverse-phase highperformance liquid chromatography (HPLC) ${ }^{31}$ RP-HPLC is chosen because its compatibility with aqueous and organic solutions, high precision, sensitivity and ability to detect polar compounds. Further a prominent method development is done by selecting appropriate column type, column temperature, and making an adjustment to mobile phase $\mathrm{pH}^{32,33}$ Early elution of highly polar compounds and retention of non polar compounds achieved through gradient elution. Various environmental condition stressed samples can also elute by gradient elution. Solvents and mobile phase should be compatible with the drug substances. ${ }^{34}$ Acidic and basic stressed samples should be neutralised before analysis Dilution of samples should be carried out depending on the analytical technique used. The calculation should not include blank. Based on stability results degradation product identification and characterization shall be performed with ICH requirements $s^{6,34}$ Conventional methods (e.g., column chromatography) or hyphenated techniques (e.g., LC MS, LCNMR) can be used in the identification and characterization of the degradation products. LCMSMS play a significant role in the development of whole degradation pathway of the drug molecule. The fragments of the drug substance will facilitate the development of degradation pathway. ${ }^{35}$

By suitable LC-MS conditions, the mass numbers of impurities/ degradants get confirm and further identify the mass of major degradants which are found to be forming greater than $1.0 \%$ during stress studies. LCMS help to illustrate the structures of the major degradants. Similar molecular weights compound may exhibit similar UV profiles, in such cases; attempts must be made to modify the chromatographic parameters to achieve necessary separation. To detect and quantitation of all the potential impurities and degradants an optimal wavelength should be used. The developed method should be validated as per the ICH guidelines. ${ }^{36-38}$

\section{Conclusion}

Forced degradation studies are the prominent way to develop degradation pathways and to identify the degradation products of the active ingredients, further it facilitates the elucidation of degradants structure. Forced degradation studies also facilitate the chemical and physical stability analysis of drug substances and drug products. This assists to develop formulation manufacturing conditions, storage conditions and determine the expiry date of a drug formulation.

\section{Acknowledgments}

None.

\section{Conflicts of interest}

Author declares there are no conflicts of interest.

\section{Funding}

None.

\section{References}

1. ICH. Stability testing of new drug substances and products Q1A (R2), IFPMA, Geneva, Switzerland. 2003.

2. Center for Biologics Evaluation and Research (US). Guidance for industry Q1B photo stability testing of new drug substances and products in U.S. Dept of Health and Human Services. Food and Drug Administration Center for Biologics Evaluation and Research, Rockville, MD. 1996. p.11-15. 
3. Center for Biologics Evaluation and Research (US). Guidance for industry Q1A (R2) stability testing of new drug substances and products in U.S. Dept of Health and Human Services. Food and Drug Administration Center for Biologics Evaluation and Research, Rockville, MD. 2003;22-26.

4. Center for Biologics Evaluation and Research (US). Guidance for industry Q1E evaluation of stability data in U.S. Dept of Health and Human Services. Food and Drug Administration Center for Biologics Evaluation and Research, Rockville, MD. 2004;18-26.

5. Center for Drug Evaluation and Research (US) .Guidance for industry Q1A (R2) stability testing of new drug substances and products in U.S. Dept of Health and Human Services. Food and Drug Administration Center for Biologics Evaluation and Research, Rockville, MD. $2003 ; 22-28$.

6. ICH. Impurities in new drug products, IFPMA, Geneva, Switzerland. 1996.

7. Brummer H. How to approach a forced degradation study. Life Sci Technol Bull. 2011;31:14.

8. Ranjit S, Rehman Z. Current trends in forced degradation study for pharmaceutical product development. Journal of pharmaceutical and educational research. 2012. p. 54-63.

9. Maheswaran R. FDA perspectives: scientific considerations of forced degradation studies in ANDA submissions. Pharmaceutical Technology. 2012;36(5):73-80.

10. Kovarikova P, Jiri K, Jiri D, et al. HPLC study of glimepiride under hydrolytic stress conditions. J Pharm Biomed Anal . 2004;36(1):205-209.

11. FDA. Guidance for Industry, INDs for Phase II and III StudiesChemistry, Manufacturing, and Controls Information. Food and Drug Administration. 2003. p. 1-27.

12. Singh S, Bakshi M. Guidance on conduct of stress tests to determine inherent stability of drugs. Pharma Tech. 2000;24:1-14.

13. ICH Q3C (R3). Impurities: Guidelines for Residual solvents (Step 5), International Conference on Harmonization. 2002.

14. Boccardi G. . Oxidative susceptibility testing in pharmaceutical stress testing predicting drug degradation. Tn: Baertschi SW (Eds.), Taylor and Francis, New York, USA. 2005.

15. Alsante KM, Hatajik TD, Lohr LL, et al. Solving impurity/degradation problems: case studies. In: Ahuja S \& Alsante K (Eds.), Handbook of Isolation and Characterization of impurities in Pharmaceutical, Academics Press, New York, USA. 2003.

16. Oyler AR, Segmuller BE, Sun Y, et al. Forced degradation studies of rapamycin: Identification of autoxidation products. J Pharm Biomed Anal. 2012;59:194-200.

17. Trabelsi H, Hassen IE, Bouabdallah S, et al. Stability indicating LC method for determination of Pipamperone. J Pharm Biomed Anal . 2015;39(5):914-919.

18. Dorman DE, Lornez LJ, Occolowitz JL, , et al. Isolation and structure elucidation of the major degaradation products of cefaclor in the solid state. J Pharm Sci. 1997;86(5):526-539.

19. Prekodravac B, Damm M, Kappe CO. Microwave-assisted forced degradation using high-throughput microtiter platforms. J Pharmaceut Biomed. 2011;56(5):867-873.
20. FDA. Guidance for Industry INDs for Phase 2 and 3 Studies of Drugs, Including Specified Therapeutic Biotechnology- Derived Pro- ducts, Draft Guidance, Food and Drug Administration. 1999. p. 1-18.

21. Baertschi SW, Thatcher SR. Sample presentation for photostability studies: problems and solutions. In: Piechocki J \& Thoma K (Eds.), Pharmaceutical Photostability and Stabilization Technology. Taylor \& Francis, New York, USA. 2006. p.445.

22. Baertschi SW, Alsante KM. Stress testing: the chemistry of the drug degradation. Pharmaceutical Stress Testing, Taylor \& Francis, New York, USA. 2005. p.99.

23. Reynolds DW, Facchine KL, Mullaney JF, et al. Available guidance and best practices for conducting forced degradation studies. Pharm Technol .2002;26(2):48-56.

24. Ali NW, Abbas AS, Zaazaa HE. Validated stability indicating methods for determination of Nitazoxanide in presence of its degradation products, J Pharm Anal. 2012;2(2):105-116.

25. Riddhiben MP, Piyushbhai MP, Natubhai MP. Stability indicating HPLC method development-a review. Int Res J Pharm. 2011;2(5):79-87.

26. Annapurna MM, Mohapatro CM, Narendra A. Stability indicating liquid chromatographic method for the determination of Letrozolein pharmaceutical formulation. J Pharm Anal. 2012;2(4):298-305.

27. Kats M. Forced degradation studies: regulatory considerations and implementation. Bio Pharm Int. 2005;18(7):1-7.

28. Alsante KM, Ando A, Brown R. The role of degradant profiling in active pharmaceutical ingredients and drug products. Adv Drug Deliv Rev. 2007;59(1):29-37.

29. Gupta A, Yadav JS, Rawat S. Method development and hydrolytic degradation study of Doxofylline by RP HPLC and LC-MS/MS. Asian J Pharm Anal. 2011;1(1): 14-18.

30. Allwood M, Plane J. The wavelength-dependent degradation of vitamin A exposed to ultraviolet radiation. Int J Pharm. 1986;31(1-2): 1-7.

31. ICH Q3A (R2). Impurities in New Drug Substances and Products (Step 4), International Conference on Harmonization. 2006. p. 1-15.

32. Shirazi D, Ware E, Harper T, et al. The Benefits of Using AAI Pharma Services for Elemental Impurity Analysis Using ICP-MS Technology. Am PharmaceutRev. 2012. p.1-10.

33. Matthews BR. Regulatory aspects of stability testing in Europe. Drug Dev Ind Pharm. 1999;25(7):831-856.

34. Skoog DA, West DM, Holler FJ. Analytical Chemistry, An Introduction. Saunders College Publishing, Philadelphia, USA. 2002. p.3-11.

35. Sitaram C, Rupakula R, Reddy BN. Determination and characterization of degradation products of Anastrozole by LC MS/MS and NMR spectroscopy. J Pharm Biomed Anal. 2011;56(5):962-968.

36. Skoog DA, West DM. Principles of Instrumental Analysis. Saunderg Golden, Japan. 1980. p.2-3.

37. Dolan J. Stability-indicating assays: LC trouble shooting. $L C-G C N A m$. 2002;20(4): 346-349.

38. Smela JW. Regulatory considerations for stability indicating analytical methods in drug substance and drug product testing. Am Pharm Rev. $1980 ; 8(3): 51-54$. 